\title{
Pengembangan Bahan Ajar Komik Berbasis Cerita Rakyat Bengkulu di SD
}

\author{
Abdul Muktadir \\ Universitas Bengkulu \\ abdulmuktadir@unib.ac.id \\ Ady Darmansyah \\ Universitas Bengkulu \\ adydarmansyah45@gmail.com
}

\begin{abstract}
The purpose of this study was to develop folklore-based comics teaching materials in Bengkulu City elementary schools. The method used is Research and Development using the ADDIE (Analysis-Design-Develop-Implement-Evaluate) model. However, this research is only in the Analysis-Design-Develop stage. Research data from interviews and questionnaires, interview data sources, observations, and documentation. The research instrument for analyzing the needs of teachers and students is in the form of a list of questions and questionnaires, descriptive data analysis. The results of the study were folklore-based comics in elementary schools in Bengkulu City. Folklore material is taught only at the competency stage. The competence of teachers regarding folklore is not sufficient, meaning that one story has not been fully understood, the number of stories known by the teacher does not exceed five stories.
\end{abstract}

Keywords:Comics Teaching Materials, Folklore, Elementary School.

\section{Pendahuluan}

Cerita rakyat bagian kebudayaan tradisional yang dimiliki setiap kelompok etnis, penyebarannya secara lisan dan turun-temurun. Penyebaran cerita rakyat secara lisan ini menyebabkan keberadaan cerita semakin terpinggirkan, dan pada gilirannya dikhawatirkan akan hilang. Hasil penelitiaan Gusal (2015) menyimpulkan bahwa cerita rakyat yang ada pada masyarakat Sulawesi Tenggara sudah mulai terlupakan. Penelitian Rozie (2019: 28), menyimpulkan cerita rakyat sebagai salah satu hiburan masyarakat tenggelam oleh cerita sinetron, dengan alasan sinetron lebih nyata alurnya sehingga mudah dipahami dan dinikmati.

Cerita rakyat merupakan media yang mengemas nilai-nilai dan bisa menjadi sumber imajinasi. Rohinah (2011: 13) menyatakan nilai-nilai yang terkandung dalam cerita rakyat sebagai bagian sastra secara tidak langsung dapat merekonstruksi sikap dan kepribadian anak. Sulistyorini (2017: 1) menjelaskan cerita rakyat merupakan media komunikasi budaya yang mengandung nilai luhur yang dapat digunakan untuk menyampaikan pesan dan kontrol sosial bagi kehidupan manusia.

Berdasarkan analisis buku siswa Kurikulum 2013, diterbitkan oleh Pusat Kurikulum dan Perbukuan (2017), tidak ditemukan cerita rakyat Bengkulu. Para guru saat ini tampaknya belum terbiasa merancang bahan ajar. Prastowo (2012: 18) menyatakan para pendidik cenderung menggunakan bahan ajar yang ada, akibatnya dimungkinkan bahan ajar yang digunakan tidak kontekstual. Komik bacaan yang paling digemari pembaca. Nurgiyantoro (2019: 419). menyatakan komik bacaan yang paling digemari pembaca anak-anak, juga orang dewasa. Kustandi \& Darmawan (2020: 145) menjelaskan komik sangat berpengaruh dalam memberi pemahaman dengan cepat kepada pembaca. Bahasa, gambar, dan teks yang digunakan mampu 
mentransfer pemahaman atau informasi dengan cepat dibandingkan hanya menggunakan tulisan saja.

Wyat dan Looper dalam Akbar (2013: 114), menyatakan anak pada usia Sekolah Dasar lebih menyukai dan mudah menangkap informasi dengan visual yang memiliki gambar dan warna, dengan daya ingat sebesar (30\%) dari pada membaca teks, dengan daya ingat sebesar (10\%). Anak aktif berfikir kreatif, meningkatkan rasa ingin tahu, dan juga memperluas ilmu pengetahuan dan kosa kata mereka. Tim Fame-Me (2013: 12) menyatakan visualisasi dapat menyentuh perasaan terdalam. Kesan melalui visualisasi mempertahankan kompleksitas yang tidak dapat dilakukan leh verbal dengan cara tertentu. Pendapat Danandjaja (1997: 19), menyatakan bahwa cerita rakyat sangat penting untuk diajarkan karena di dalamnya terdapat nilai yang dapat dijadikan pembelajaran untuk membimbing anak agar berperilaku baik, sebagai sistem proyeksi angan-angan, alat pengesahan budaya, alat pendidikan, dan alat pemaksa berlakunya norma-norma masyarakat dan kontrol sosial dalam bertingkah laku maupun bertindak. Sehubungan dengan masalah yang dikemukakan maka diperlukan kemampuan guru dalam memilih atau merancang bahan ajar berbasis cerita rakyat Bengkulu.

Bahan ajar dirancang berbentuk komik agar lebih menarik. Hasil penelitian Sarkadi \& Iqbal (2020) tentang "Teaching Materials of Thematic Comics in the 2013 Curriculum Learning in Basic Schools”. Dari penelitian tersebut menyimpulkan bahwa pembelajaran komik memiliki daya tarik bagi siswa karena di dalamnya menyajikan visualisasi gambar yang imajinatif dan berwarna. Penelitian yang dilakukan oleh Lubis (2017) tentang "The Using of Comic as a Teaching Material in Building Character of Elementary School Students". Hasil penelitian menjelaskan bahwa komik bahan ajar yang efektif terutama di Sekolah Dasar, karena komik mengandung gambar dan cerita berkarakteristik yang mampu membangun karakter siswa. Danandjaja (1997: 1) menyatakan bahwa: 1) cerita rakyat adalah cerita yang dianggap pernah terjadi dimasa lampau yang disampaikan kepada orang lain; 2) isi ceritanya merupakan pesan atau amanat; dan 3) setiap cerita mempunyai tokoh. Menurut Danandjaja (1997: 19), bahwa fungsi cerita rakyat, yaitu sebagai: alat pengesahan pranata dan lembaga-lembaga kebudayaan, alat pemaksa dan pengawas agar norma-norma masyarakat akan selalu dipatuhi anggota kolektifnya, pendidikan anak, dan sistem proyeksi (alat pencermin anggan-angan kolektif).

Komik menurut Scott dalam Kustandi \& Darmawan (2020: 142) memberikan pengertian tentang komik, adalah gambar-gambar dan lambang-lambang lain yang terjukstaposisi dalam urutan tertentu untuk menyampaikan informasi mencapai tanggapan estetis dari pembaca. Langkah pembuatn komik menurut Muharsi dalam Kustandi \& Darmawan (2020 : 150-153) ada 11 langkah, yaitu membuat Garis Besar Isi Media (GBIM), membuat sinopsis cerita (tema, plot, dan setting cerita), membuat storyline, mendesain karakter tokoh, membuat storyboard, membuat sketsa pensil, menebalkan sketsa pensil dengan tinta, merapikan gambar, scan gambar ke dalam komputer, mengedit dan memberi teks, tahap layout, serta yang terakhir tahap percetakan.

\section{Metode}

Metode penelitian ini menggunakan metode penelitian pengembangan atau Research and Development $(R \& D)$. Research and Development adalah suatu penelitian untuk menghasilkan sebuah produk baru (Sugiyono, 2016: 29). Dalam penelitian pengembangan ini menggunakan Model Desain Pembelajaran ADDIE (AnalysisDesign-Develop-Implement-Evaluate), namun hanya sampai pada tahap pengembangan. Data penelitian wawancara, dokumen, dan observasi. Analisis data 
adalah analisis deskriptif kualitatif untuk mengolah data berupa catatan, saran, atau komentar berdasarkan hasil instrumen analisis kebutuhan dari wawancara berisi pertanyaan untuk lima guru dan angket untuk sepuluh peserta didik di SDN 82 Kota Bengkulu. Pada tahap analisis disimpulkan kurangnya bahan ajar yang digunakan guru dalam menyampaikan materi. Pada tahap perencanaan (Design) telah dikembangkan rangkaian gambar sesuai alur cerita "Sayembara Pandai Tidur" pada tahap ini juga ditentukan software yang digunakan saat pengembangan. Selanjutnya tahap pengembangan (Development) yakni proses membuat sketsa cerita berdasarkan alur cerita menjadi gambar-gambar komik dan menggunakan software.

\section{Hasil}

Bahan ajar yang dikembangkan cerita rakyat: "Sayembara Pandai Tidur" cerita rakyat Bengkulu. Tahap pertama analysis (analisis), dilakukan analisis kurikulum, analisis kebutuhan, dan analisis karakteristik peserta didik. Analisis kurikulum untuk memilih Kompetensi (KD) cerita yakni. KD 3.9 dan KD 4.9 dan dijabarkan menjadi indikator dan tujuan pembelajaran. Selanjutnya analisis kebutuhan bahan ajar pengguna yakni guru menggunakan daftar pertanyaan, peserta didik menggunakan angket. Berdasarkan wawancara dan angket diperlukan bahan ajar bergambar berasal dari cerita rakyat Bengkulu.

Berdasarkan instrumen analisis kebutuhan ditemukan permasalahan pembelajaran cerita rakyat. Dari hasil wawancara kepada lima guru dan angket kepada sepuluh peserta didik SDN 82 Kota Bengkulu diperoleh informasi bahwa pembelajaran cerita rakyat kurang optimal, artinya pembelajaran yang berkaitan dengan materi cerita rakyat hanya menekankan kompetensi pengetahuan dan belum mencapai kompetensi keterampilan. Para guru tidak bercerita, tidak melatih siswa bercerita, dan tidak menugaskan peserta didik mencari cerita rakyat dari berbagai sumber. Kompetensi guru berkaitan cerita rakyat kurang memadai secara kualitas dan kuantitas.

Analisis kebutuhan dilanjutkan analisis karakteristik peserta didik. Karakteristik peserta didik perlu untuk menentukan isi, bahasa, dan penyajian cerita. Isi cerita berkaitan dengan alur cerita diedit, kosa kata yang tidak perlu dihilangkan sehingga menjadi kalimat sederhana, dan penyajian dilengkai gambaar untuk memudahkan pemahaan cerita.

Tahap kedua yakni design (desain). Peneliti merancang bahan ajar cerita rakyat dengan memilih tema, mengedit alur cerita, menulis naskah cerita, membuat gambar komik, membuat dialog dalam balon kata. Desain produk terdiri dari cover, $\mathrm{KD}$, dan isi cerita yang disesuaikan dengan gambar-gambar. Tahap ketiga development (pengembangan), yakni membuat bahan ajar bergambar dari cerita yang sudah diedit menjadi sketsa cerita sesuai dengan balon kata. Pengembangan bahan ajar ini belum sampai tahap validasi.

Untuk mengatasi persoalan yang muncul dalam pembelajaran cerita rakyat maka dirancanglah bahan ajar komik berbasis cerita rakyat. Rancangan bahan ajar sesuai dengan tujuan pembelajaran, sumber belajar dan aspek bahan ajar meliputi aspek isi (cerita rakyat sayembara pandai tidur), aspek bahasa (ejaan, tanda baca, kosa kata, dan paragraf), dan aspek kegrafikan (tata letak, ilustrasi, jenis huruf, ukuran huruf, dan warna). Adapun pengembangan bahan ajar komik berbasis cerita rakyat Bengkulu yakni: pada tampilan cover komik memperlihatkan judul komik dan terdapat gambar serta tulisan yang berkaitan dengan judul komik (gambar 1), pada tampilan isi komik terdapat KD dan indikator sesuai materi pembelajaran pada 
tema, subtema, dan dialog tokoh dalam komik (gambar 2), dan pada tampilan evaluasi terdapat soal evaluasi yang sesuai dengan pembahaasan materi pembelajaran (gambar 3).

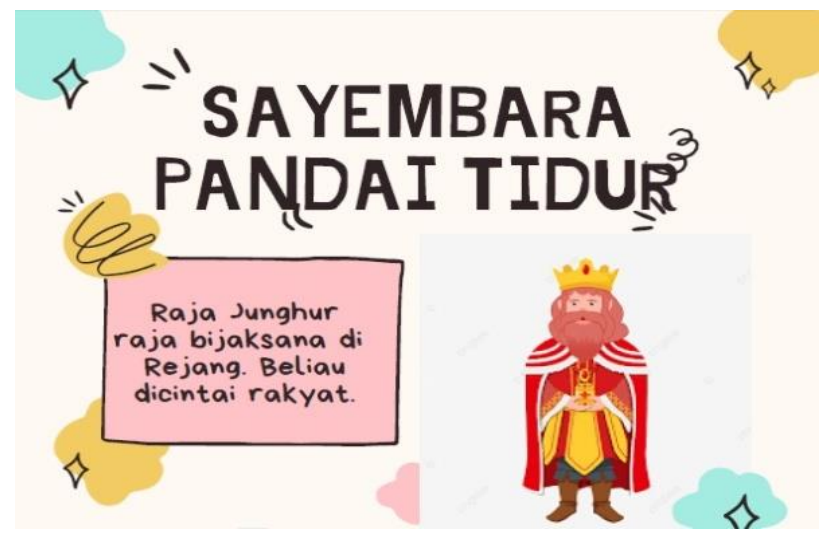

Gambar 1. Tampilan Cover Komik

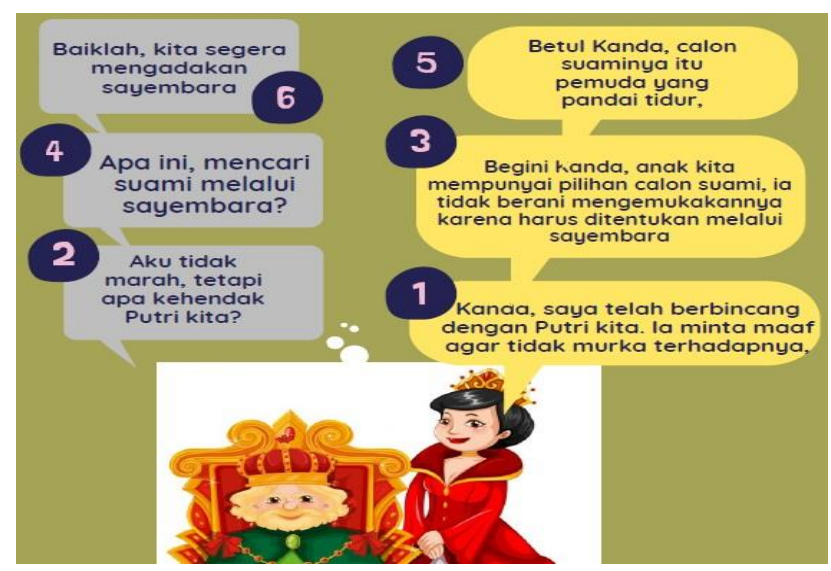

Gambar 2. Tampilan Isi Komik

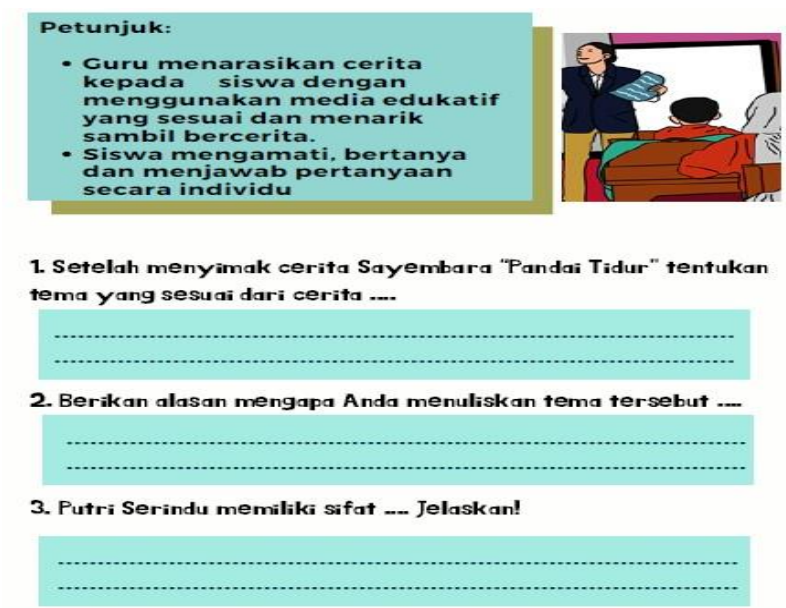

Gambar 3. Tampilan Evaluasi Kegiatan dalam Komik

\section{Pembahasan}

Pengembangan bahan ajar komik berbasis cerita rakyat perlu dilakukan. Pengembangan bahan ajar ini untuk melengkapi bahan ajar yang ada dan bahan ajar yang belum kontekstual. Bahan ajar komponen penting dalam kelancaran 
pembelajaran. Guru dapat merancang, melaksanakan, dan mengevaluasi pembelajaran sesuai dengan tujuan pembelajaran jika kelengkapan pembelajaran terpenuhi, umpamanya ketersediaan bahan ajar. Siswa pun dapat mengikuti pembelajaran optimal jika bahan ajar yang diperlukan tersedia. Oleh sebab itu diperlukan kreativitas guru agar bahan ajar yang dibuat sesuai dengan tujuan dan kontekstual. Pentingnya guru merancang bahan ajar dapat dikaitkan dengan pendapat Muslich (2010: 23) yang menjelaskan bahwa guru dapat mengelola pembelajaran secara efesien dan efektif jika dilengkapi sarana bahan ajar. Siswa pun dapat mengikuti pembelajaran dengan maksimal harus dilengkapi bahan ajar. Menurut Pribadi \& Putri (2019: 1), penggunaanbahan ajar dalam proses pembelajaran akan meningkatkan minat dan motivasi peserta didik dan menjadi fasilitas bagi peserta didik pada proses pembelajaran.

Pengembangan bahan ajar komik berbasis cerita rakyat dilakukan dalam upaya melestarikan cerita rakyat dari kepunahan karena keberadaanya semakin terpinggirkan. Cerita rakyat sebagai bagian kearifan lokal merupakan media yang mengemas nilai-nilai dan efektif untuk membentuk karater melalui pendeskripsian perilaku tokoh cerita. Rohinah (2011: 38) menjelaskan sastra anak yang meliputi cerita rakyat secara tidak sadar merekonstruksi sikap dan kepribadian anak. Cerita rakyat berfungsi sebagai penanaman nilai-nilai dan karakter. Penelitian Murti, dkk (2019) tentang "Development of Educational Comic with Local Wisdom to Foster Morality of Elementary School Students: A Need Analysis". menyimpulkan pengembangan media komik dengan kearifan lokal sangat dibutuhkan untuk memenuhi kebutuhan siswa sekolah dasar sebagai upaya pembinaan karakter.

Pembelajaran budaya berdasarkan kearifan lokal adalah pembelajaran mendekatkan budaya dengan peserta didik atau sebaliknya pembelajaran yang tidak menyertakan bagian budaya dalam bahan ajar, akan menjauhkan peserta didik dari budaya. Pembelajaran bersumber dari lingkungan peserta didik akan lebih mudah dipahami peserta didik dan pembelajaran pun akan bermakna. Pentingnya pemahaman budaya oleh peserta didik dapat dikaitkan dengan pendapat Abidin (2012: 222) karya sastra mencakup cerita rakyat tepat dijadikan bahan ajar untuk eserta didik. Adanya kesamaan budaya menyebabkan siswa akan lebih cepat memahami materi pembelajaran.

Cerita rakyat merupakan gambaran masyarakat pemilik cerita dan dimiliki semua etnis. Cerita menginformasikan berbagai nilai-nilai, peristiwa yang terjadi atau kebiasaan di masyarakat asal cerita. Pembelajaran dengan memanfaatkan bahan ajar komik berbasis cerita rakyat pembelajaran penanaman nilai-nilai untuk pembentukan karakter juga dapat melatih imajinasi anak. Melalui teks bacaan secara tidak langsung terjadi proses internalisasi nilai dan gambar-gambar anak akan terlatih membayangkan peristiwa yang sesungguhnya. Al-Khalili (2005: 187) menyatakan menyajikan dan menganalisis cerita dalam pembelajaran akan mengajarkan nilai-nilai yang terkandung dalam cerita kepada anak, juga tradisi dan perilaku yang diharapkan anak dapat meniru sifat-sifat tersebut, sedangkan penyajian gambar dalam cerita akan dapat mengembangkan imajinasi anak. Lwin (2008: 77) menyatakan gambar-gambar membantu anak mengembangkan imajinasinya yang akan menjadikan anak lebih kreatif, juga memperkaya proses berpiir tingkat tinggi.

Berdasarkan daftar pertanyaan yang diberikan kepada guru dan angket yang diisi siswa menginginkanbahan ajar komik berbasis cerita rakyat. Hal ini dapat dipahami karena selain bahan ajar berbasis cerita juga rancangan komik ini belum pernah digunakan dalam pembelajaran. Karakteristik komik berupa gambar-gambar, biasanya disukai pembaca. Penelitian Phoon (2020) tentang "The Role of Comics in Elementary School". Berdasarkan hasil penelitian menjelaskan bahwa para siswa 
ternyata tertarik, terlibat, dan antusias dalam penggunaan komik sebagai terungkap dari analisis tematik wawancara.

\section{Simpulan}

Bahan ajar komik berbasis cerita rakyat memperkaya bahan ajar yang ada dan membantu guru dalam pembelajaran materi bercerita. Cerita rakyat Bengkulu tidak ditemukan dalam buku siswa yang terbit tahun 2017. Bahan ajar menggunakan cerita rakyat Bengkulu merupakan sarana yang strategis dalam mewariskan kelestarian cerita rakyat yang semakin tidak dikenal. Pembelajaran cerita rakyat tampaknya menjadi pembelajaran yang kurang diminati para guru. Kompetensi para guru bercerita secara keseluruhan satu cerita dan kometensi jumlah cerita yang diketahui belum memadai. Pembelajaran materi bercerita rakyat hanya kompetensi pengetahuan saja.

\section{UcapanTerima Kasih}

Ucapan terima kasih disampaikan kepada Redaktur Ahli Jurnal FKIP Pendidikan Guru Sekolah Dasar Universitas Bengkulu yang telah memberikan masukan, catatan penting, dan pembenahan aspek kebahasaan untuk penyempurnaan artikel ini. Semoga artikel ini bermanfaat dalam pengembangan kearifan lokal dalam matapelajaran Bahasa Indonesia sebagai bahan ajar dan buku bacaan untuk siswa sekolah dasar.

\section{Referensi}

Abidin, Y. (2012). Pembelajaran Bahasa Berbasis Pendidikan Karakter. Bandung: Refika Aditama

Al-Khalili, A. (2005). Mengembangkan Kreativitas Anak. Jakarta: Al-Kautsar.

Akbar, S. (2013). Instrumen Perangkat Pembelajaran. Bandung: PT Remaja Rosdakarya.

Danandjaja, J. (1997). Folklor Indonesia: Ilmu Gosip, Dongeng, dan lain lain. Jakarta: PT Pustaka Utama Grafiti.

Gusal, L. O. (2015). Nilai-Nilai Pendidikan dalam Cerita Rakyat Sulawesi TenggaraKarya La Ode Sidu. Jurnal Humanika. 15(3). 1-18.

Kemendikbud. (2017). Panduan Penilaian oleh Pendidik dan Satuan Pendidikan untuk Sekolah Menengah Atas. Jakarta: Direktorat Jenderal Pendidikan.

Kustandi, C.\& Darmawan, D. (2020). Pengembangan Media Pembelajaran. Jakarta: Kencana.

Lubis. (2017). The Using of Comic as a Teaching Material in Building Character of Elementary School Students.Journal of Madrasah Ibtidaiyah Education. 1 (2). 246-258.

Lwin, May. (2008)Cara Mengembangkan Berbagai Komponen Kecerdasan, Jakarta: PT. Indeks.

Murti, D. K. Gunarhadi, \& Winarno (2020). Development of Educational Comic with Local Wisdom to Foster Morality of Elementary School Students: A Need Analysis. International Journal of Educational Methodology. 6 (2). 337-343.

Nurgiyantoro, B. (2019). Teori Pengkajian Fiksi. Cetakan 1X.Yogyakarta: Gajah Mada University Press.

Rozie, M. (2019). Analisis Nilai-Nilai Sosial Dalam Kumpulan Cerita Rakyat Bangka Belitung. Jurnal Ilmiah Bina Bahasa. 12(2). 27-38. 
Rohinah, M.N. (2011). Pendidikan Karakter Berbasis Sastra Solusi Pendidikan Moral yang Efektif. Yogyakarta: AR-Ruzz Media.

Sarkadi \& Iqbal, A. M. (2020). Teaching Materials of Thematic Comics in the 2013 Curriculum Learning in Basic Schools. Jurnal Pendidikan Indonesia. 9(4). 618-627.

Sulistyorini, D. \& Andalas, E. F. (2017). Sastra Lisan: Kajian Teori Dan Penerapannya Dalam Penelitian. Malang: Madani.

Sugiyono. (2016). Metode Penelitian Bisnis. Pendekatan Kuantitatif, Kualitatif dan $R$ $\& D$. Bandung: Alfabeta.

Phoon, H. Y. Roslan, R. \& Shahrill, M. (2020). The Role of Comics in Elementary School Science Education. Jurnal Ilmiah Pendidikan MIPA. 10 (2). 67-76.

Prastowo. A. (2012). Panduan Kreatif Membuat Bahan Ajar Inovatif.Yogyakarta: Diva Press.

Pribadi, B. A. \& Putri, A. P.(2019). Pengembangan Bahan Ajar. Tangerang Selatan: Universitas Terbuka. 